\title{
Contamination rate of commonly consumed fresh vegetables and fruits with parasites of medically importance in Wolkite and Butajira Towns of Gurage Zone, Southern Ethiopia
}

\author{
Fitsum Bekele ${ }^{1}$, Teha Shumbej ${ }^{2}$, Andamlak Dendir $^{3}$, Dereje Mesfin $^{4}$, Absra Solomon $^{5}$, \\ Abduelwhab Jemal ${ }^{6}$, Mihret Alemayheu ${ }^{7}$ \\ ${ }^{1,2,5,7}$ Department of Medical Laboratory Sciences, College of Medicine and Health Sciences, \\ Wolkite University, Ethiopia \\ ${ }^{3,4}$ Department of Public Health, College of Medicine and Health Sciences, Wolkite University, Ethiopia \\ ${ }^{6}$ Department of Pharmacy, College of Medicine and Health Sciences, Wolkite University, Ethiopia
}

\section{Article Info}

Article history:

Received Nov 11, 2019

Revised Mar 30, 2020

Accepted May 15, 2020

\section{Keywords:}

Gurage Zone

Intestinal helminthes

Parasitic contamination of fruits

Vegetables

\begin{abstract}
Intestinal parasitic infections are among the most common on causes of disease in humans, responsible for considerable morbidity and mortality. Commonly consumed raw vegetables and fruits are among the ways through which humans become infected with parasites of medical importance. A prospective cross-sectional study with an aim of describing the parasite contamination rate of raw fresh vegetables and fruits sold at the central open-aired market of Butajira and Wolkite towns, in southern Ethiopia was conducted on a total of 270 fresh vegetable and fruits samples. Standardized parasitological techniques were employed to detect diagnostic stages of parasites.98 out of the 270 (36.3\%) samples were found positive for intestinal parasites. Remarkably, twenty eight out of the forty five cabbage samples analyzed, $62.2 \%$, were found to be contaminated with parasites of medical importance, registering the highest level of contamination. On the contrary Avocado was found to be the least contaminated produce with contamination rate of $17.7 \%$ (8/45). Significant association was observed between the kind of vegetables analyzed and existence of parasites $(\mathrm{p}=0.002)$. This study identified high rate of contamination in commonly consumed vegetables and fruits. The authors believe that the role fruits and vegetables paly in the transmission of intestinal parasitic infections to humans is un questionable. Substantial attention is needed from all relevant bodies to tackle this problem.
\end{abstract}

This is an open access article under the CC BY-SA license.

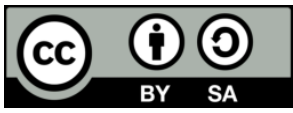

\section{Corresponding Author:}

Fitsum Bekele

Department of Medical laboratory Sciences,

College of Medicine and Health Sciences, Wolkite University,

Wolkite Ethiopia.

Email: fbt1019@yahoo.com

\section{INTRODUCTION}

Soil transmitted helminthic and protozoan infections represents a large and serious public health problem in poor countries. It is estimated that around 3.5 billion people are affected worldwide [1]. Studies show that Infections with medically intestinal helminths and protozoans are closely linked with conditions of poverty, unsafe water, crowded living conditions, lack of sanitation and hygiene $[2,3]$. Food borne diseases are a major cause of morbidity and continue to be a common and serious threat to public 
health all over the world; as fresh vegetables are eaten raw or lightly cooked to preserve the taste and their nutrient content, this act as a potential source of various foodborne infections and disease outbreaks [4].

Findings from Studies conducted in Egypt; Libya; Saudi Arabia; Iraq, Iran, the Philippines, and Ethiopia have stressed that fruits and vegetables, particularly which are consumed raw and unwashed, play a significant role in the transmission of medically important parasites [5-14]. Globally, Outbreaks resulting from consumption of raw vegetables contaminated with parasites have been reported from both rich and poor countries [15-17]. Poor hygienic practices related to planting, harvesting, packing, transportation, and storage, fruits and vegetables can expose vegetables and fruits to be contaminated with parasites of clinical significance [14].

In spite of the fact that there exists an increased advocate for the consumptions of fresh fruits and vegetables worldwide, it is greatly threatened by an upsurge of parasitic contamination. Despite a marked improvement in sanitation, Ethiopians still suffer from poor sanitation and low standard living conditions which exposes them to an increased risk of acquiring parasitic infections. To the best of our knowledge, there is no published document about the level of parasitological contamination of fruits and vegetables in our study area. Therefore, this study was designed to determine the level of parasitic contamination of selected fruits and vegetables and associated factors in this location.

\section{RESEARCH METHOD}

\subsection{Study area}

Gurage Zone is one of the administrative zones of Ethiopia which is found in Southern Nations, Nationalities, and Peoples' Region. Wolkite, with a total population of $28,866.00$ is currently the administrative city of the Zone. Geographically the town lies 1910 and 1935 meters above sea level. Whereas, Butajira, with a total population of 33,406 , is the largest city in this zone and the former administrative center. The town lies 2131 meters above sea level.

\subsection{Sample collection and analysis}

The are 270 vegetable samples of 6 different types, 45 each, such as carrot, cabbage, lettuce, tomato, green pepper and avocado were collected from central markets of the two towns. Each vegetable sample was chopped into pieces and weighted to 200 grams. Chopped samples were washed in separate beakers in $500 \mathrm{~mL}$ of normal saline for detaching any parasitic stages .After the washing solution was left to stand for twelve hours, $15 \mathrm{~mL}$ of the sediment was transferred to a centrifuge tube, so as to remove undesirable matters. Finally, the tube was centrifuged at $3000 \mathrm{rpm}$ for five minutes [18], the supernatant was decanted and the sediment was agitated and examined under a compound Olympus light microscope.

\subsection{Data analysis}

Data was analyzed by using SPSS software version 16 (IBM, Chicago, IL, USA). A P-value of equal to or less than 0.05 was considered statistically significant. The Pearson's Chi-square test $(\chi 2)$ was used for comparing rate of parasitic contamination among different categories.

\subsection{Ethical issue}

All who were present during the data collection period were briefed about the study objectives and samples were collected only from those who agreed to participate.

\section{RESULTS AND DISCUSSION}

Among 270 samples analyzed, 98 were found to be infested with at least one and at most seven different types of parasites Table 1; the total contamination rate was $36.3 \%$. Helminthes such as A. lumbricoides, Toxocara spp., Hymenolepis spps, I. belli, and protozoans such as G. intestinalis and E. histolytica/dispar were the parasites detected Table 2. Greater than one parasite species were observed in all samples. Significant association was observed between the kind of vegetables analyzed and existence of parasites $(\mathrm{P}=0.002)$ a shown in Table 3 .

As much as microorganisms play important roles in the ecosystem, they also pose lots of threats to healthy living when they are found at the wrong place, above the required number, and their growth and movement are not controlled. As fresh vegetables are eaten raw or lightly cooked to preserve the taste and their nutrient content, this act as a potential source of various foodborne infections and disease outbreaks. The favorable climatic conditions and unsanitary practices that contribute to fecal pollution of water, foodstuffs, and soil has contributed to the wide distribution of intestinal parasites in Ethiopia, like many developing countries $[3,11]$. The present study attempted to assess the level of contamination and prevalence 
of different intestinal parasites in six different types of fruits and vegetables which are routinely consumed and sold in central markets of Butajira and Wolkite Town, Southern Ethiopia. When compared with studies from other parts of the country and elsewhere a slightly lower rate, 36.3\%, of parasitic contamination of edible fruits and vegetables was found in our study areas [14, 15, 18-20].

Table 1. Prevalence rate of parasitic contamination in fruits and vegetables in Wolkite and Butajira Towns

\begin{tabular}{ccccccr}
\hline \multirow{2}{*}{ Type of vegetable } & $\begin{array}{c}\text { Sample } \\
\text { analyzed }\end{array}$ & $\begin{array}{c}\text { Number } \\
\text { positive [\%] }\end{array}$ & One [\%] & Two [\%] & Three [\%] & Four [\%] \\
\hline Avocado & 45 & $8[17.7]$ & $6[13.3]$ & $1[2.2]$ & $1[2.2]$ & 0 \\
Lettuce & 45 & $18[40.0]$ & $15[33.3]$ & $2[4.4]$ & $1[2.2]$ & 0 \\
Carrot & 45 & $13[28.9]$ & $8[17.7]$ & $2[4.4]$ & $2[4.4]$ & $1[2.2]$ \\
cabbage & 45 & $28[62.2]$ & $24[53.3]$ & $2[4.4]$ & $1[2.2]$ & $1[2.2]$ \\
Green pepper & 45 & $16[35.6]$ & $13[28.9]$ & $1[2.2]$ & $1[2.2]$ & $1[2.2]$ \\
Tomatoes & 45 & $15[33.3]$ & $103[35.6]$ & $1[2.2]$ & $1[2.2]$ & 0 \\
Total & 270 & $98[36.3]$ & $169[62.5]$ & $9[3.3]$ & $7[2.6]$ & $3[1.1]$ \\
\hline
\end{tabular}

Table 2. Frequency and prevalence of medically important intestinal parasites in fruits and vegetables Wolkite and Butajira Towns

\begin{tabular}{ccc}
\hline Parasite species detected & Frequency & Prevalence \\
\hline Ascaris lumbricoides & 34 & $12.6 \%$ \\
Toxocara spp. & 28 & $10.3 \%$ \\
Hymenolepis nana & 30 & $11.1 \%$ \\
Entamoeba histolytica/dispar & 24 & $8.8 .4 \%$ \\
Giardia intestinalis & 22 & $8.1 \%$ \\
H. diminuta & 23 & $8.5 \%$ \\
H.worm & 7 & $2.6 \%$ \\
Total sample $(\mathrm{n}=270)$ & & \\
\hline
\end{tabular}

Table 3. Factors associated with parasitic contamination of fruits and vegetables Wolkite and Butajira Towns

\begin{tabular}{ccccc}
\hline \multirow{2}{*}{ Variable assessed } & \multicolumn{4}{c}{ Result } \\
\cline { 2 - 5 } & Positive [\%] & Total & $\mathrm{X}^{2}$ value & p-value \\
\hline Vendors educational status & & & & \\
Formal Education & $35[25.9]$ & 135 & 17.6 & 0.003 \\
Illiterate & $80[59.2]$ & 135 & & \\
Total & $115[42.6]$ & 270 & & \\
Type of produce & $18[40.0]$ & 45 & & \\
Lettuce & $15[33.4]$ & 45 & & \\
Tomato & $16[36.6]$ & 45 & 10.2 & 0.002 \\
Green pepper & $28[62.2]$ & 45 & & \\
Cabbage & $13[28.9]$ & 45 & & \\
Carrot & $8[17.7]$ & 45 & & \\
Avocado & $98[36.3]$ & 270 & & \\
Total & & & & \\
Washed before display & $77[67.0]$ & 170 & & \\
Yes & $38[33.0]$ & 100 & 5.9 & \\
No & $115[46.2]$ & 270 & & \\
Total & & & & \\
Means of display & $77[48.1]$ & 160 & & \\
On floor & $38[34.6]$ & 110 & 2.9 & \\
On table & $115[42.6]$ & 270 & & \\
Total & & & & \\
& & &
\end{tabular}

The difference in contamination rate which is observed between the present study and previous studies might be attributed to difference in geographical locations, variations in environmental conditions and socioeconomic status of the population. Owing to the difference in above mentioned factors it is expected that the results would differ. Additionally tradition of washing vegetables before display for selling which is observed in our study area might have contributed for a slightly low prevalence observed. Cabbage, lettuce and Green pepper were the most frequently contaminated produces observed in this study with a contamination rate of $62.2 \%, 40 \%$ and $36.6 \%$ respectively. With $17.7 \%$ Avocado stands the least contaminated produce. Relatively larger and uneven surfaces, which are the feature of Cabbage and lettuce, might have facilitated the attachment of the parasites to them easily. On the contrary, the smooth surface of tomato might have contributed to lower rate of parasitic attachment there by explaining the relatively lower contamination rate observed in this study [5]. 
In the present study, A. lumbricoides was found to be the most frequent parasite detected with a prevalence rate of $12.6 \%$. Previous studies done in southern Ethiopia, Philippines and Kenya [11, 20] also reported the predominance of the parasite. Universal distribution and the high number of eggs produced by parasite and the resistant nature of the eggs which enables it to survive unfavorable conditions might have contributed for the finding. It is known that the egg has the potential to survive in the absence of oxygen for two years at $5-10^{\circ} \mathrm{C}[21]$.

H. nana was the second most frequent parasite species observed in the present study with the prevalence of $11.1 \%$. The high prevalence obtained in this study compared with that of study from Jimma (8.3\%) and Banha, Egypt (2.8\%) might be due to variation in climatic conditions, socioeconomic status and geographical location $[18,22]$. With a prevalence of $10.3 \%$, Toxocara was the third most frequently detected parasite in this study. The fertility of the female parasite and the nature of the eggs, which may survive for up to ten years resisting harsh environmental conditions might be the reason behind its high prevalence $[23,24]$. In the present study it is observed that all kinds of fruits and vegetables included in the study were contaminated with multiple species of medically important parasites. This might indicate the persistence of intestinal parasitic infections in the area [13].

\section{CONCLUSION}

This study identified high rate of contamination in commonly consumed vegetables and fruits. The authors believe that the role fruits and vegetables play in the transmission of intestinal parasitic infections to humans is unquestionable. Substantial attention is needed from all relevant bodies to tackle this problem. Strategies to reduce the risk of acquiring intestinal parasitic infection from contaminated vegetables such as standard washing before eating raw vegetables are highly recommended.

\section{ACKNOWLEDGEMENTS}

We are very much grateful to vendors of fruits and vegetables who participated in this study.

\section{REFERENCES}

[1] World Health Organization (WHO): Control of tropical diseases. Geneva: WHO; 1998

[2] Okyay P., Ertug S., Gultekin B., Onen O., Beser E., ''Intestinal parasites prevalence and related factors in school children, a western city sample-Turkey,”' BMC Public Health, vol. 4, pp. 64, 2004.

[3] Wegayehu T., Tsalla T., Seifu B., Teklu T. 'Prevalence of intestinal parasitic infections among highland and lowland dwellers in Gamo area, South Ethiopia,', BMC Public Health, vol. 13, pp. 151, 2013.

[4] Mir, S. A., et al., "Microbiological contamination of ready-to-eat vegetable salads in developing countries and potential solutions in the supply chain to control microbial pathogens,' 'Food Control, vol. 85, pp. 235-244, 2018.

[5] Said D.E., "Detection of parasites in commonly consumed raw vegetables," Alexandria J. Med., vol. 48, no. 4, pp. 345-352, 2012.

[6] Hassan A., Farouk H., Abdul-Ghani R., "Parasitological contamination of freshly eaten vegetables collected from local markets in Alexandria, Egypt: A preliminary study: a preliminary study," Food Control, vol. 26, no. 2, pp. 500-503, 2012.

[7] Abougrain A. K. N. M. H, et al., "Parasitological contamination in salad vegetables in Tripoli-Libya," Food Control, vol. 21, no. 5, pp. 760-762, 2010..

[8] Al-Megrin W. A. I., "Prevalence of intestinal parasites in leafy vegetables in Riyadh, Saudi Arabia," Int J Zool Res., vol. 5, no. 2, pp. 20-23, 2010.

[9] Hadi A. M., "Isolation and identification of intestinal parasites from vegetables from different markets of Iraq," Bull. Iraq Natural History Museum, vol. 11, no. 4, pp. 17-25, 2011.

[10] Gharavi M. J, Jahani M. R., Rokni M. B., "Parasitic contamination of vegetables from farms and markets in Tehran," Iran J. Public Health, vol. 31, no. 4, pp. 83-86, 2002.

[11] Sia Su G.L, et al., "Assessing parasitic infestation of vegetables in selected markets in Metro Manila, Philippines," Asian Pacific J. Trop. Dis., vol. 2, no. 1, pp. 51-54, 2012.

[12] Shahnazi M., Jafari-Sabet M., "Prevalence of parasitic contamination of raw vegetables in villages of Qazvin Province, Iran," Foodborne Pathog. Dis., vol. 7, no. 9, pp. 1025-1030, 2010.

[13] Omowaye O. S., Audu P. A., "Parasites contamination and distribution on fruits and vegetables in Kogi, Nigeria," CIBTech J. Bio-Protocols, vol. 1, no. 1, pp. 44-7, 2012.

[14] Bekele F., et al., "Parasitic contamination of raw vegetables and fruits collected from selected local markets in Arba Minch town, Southern Ethiopia," Infectious Disease of Poverty, vol. 6, no. 1, pp. 19, 2017. 
[15] Nazemi S., et al., "Parasitic contamination of raw vegetables in Shahroud, Semnan," Zahedan J. Res. Med. Sci., vol. 14, no. 8, pp. 84-86, 2012.

[16] ul-Haq S., et al., "Parasitic contamination of vegetables eaten raw in Lahore," Pakistan J. Zool., vol. 46, no. 5, pp. 1303-1309, 2014

[17] Pires S. M., et al., "Attributing human foodborne illness to food sources and water in Latin America and the Caribbean using data from outbreak investigations," Int. J. Food Microbiol., vol. 152, no. 3, pp. 129-138, 2012.

[18] Tamirat Tefera, et al, "Parasitic Contamination of Fruits and Vegetables Collected from Selected Local Markets of Jimma Town, Southwest Ethiopia," International Scholarly Research Notices 2014, vol. 2014, pp. 1-7, 2014.

[19] D. O. Ogbolu, et al., "The presence of intestinal parasites in selected vegetables from open markets in south western Nigeria," African Journal of Medicine and Medical Sciences, vol. 38, no. 4, pp. 319-324, 2009.

[20] R. M. Nyarango, et al, "The risk of pathogenic intestinal parasite infections in Kisii Municipality, Kenya," BMC Public Health, vol. 8, article 237, 2008.

[21] Roberts AD., “Ascariasis: Introduction and Epidemiology and Transmission,” In: Satoskar AR, Simon GL, Hotez PJ, Tsuji M, editors. Medical Parasitology. Austin (Texas): Landes Bioscience, pp. 38-42, 2009.

[22] Ahmad Eraky M.A., "Parasitic contamination of commonly consumed fresh leafy vegetables in Benha, Egypt," J. Parasitol Res., 2014: ID. 613960. 2014.

[23] Sunil B, et al., "Assessment of parasitic contamination of raw vegetables in Mannuthy, Kerala state, India," Vet. World, vol. 7, no. 4, pp. 253-256, 2014.

[24] Klapec T., Borecka A., "Contamination of vegetables, fruits and soil with geohelmints eggs on organic farms in Poland," Ann. Agric. Environ. Med., vol. 19, no. 3, pp. 421-425, 2012. 